\title{
Power and Participation in Digital Late Modernity: Towards a Network Logic
}

\author{
Jakob Svensson \\ Karlstad University, 65188 Karlstad, Sweden \\ jakob.svensson@kau.se
}

\begin{abstract}
Through theories of mediatization it is commonly understood that political institutions and participatory practices adapt to the logics of mass media. Today the overall media and communication landscape is becoming digitalized. Technological processes of digitalization evolve in tandem with socio-cultural processes of reflexivity and individualization in late modernity. Thus politics and participation will be adapting to an increasingly digitalized and individualized media and communication landscape. This is a theoretical paper with an aim to critically analyze how contemporary media and communication landscape will influence practices of participation. Through the concept of network logic it is argued that users are disciplined into responsive and reflexive communication and practices of constant updating. As a result of this political participation will be more expressive and increasingly centered around identity negotiation.
\end{abstract}

Keywords: Digital Late Modernity, Identity, Network Logic, Political Participation, Power.

\section{New Media, New Logics?}

It is commonplace to claim the strong links between media and democracy. For example, the idea of media as a fourth estate suggests an understanding of media as an integrated part of democratic institutions and its practices, a component of the political system outside the official administrative realm [1]. Through concepts such as mediatization and media logic(s), it has been argued that media and politics no longer can be understood as two separate domains. Media is not only linked to politics and power, but described as sites out of which power and politics are exercised [2], [3], [4], [5]. This brings attention to a double-sided process in late modernity in which the media emerge as an independent institution with a logic of its own that political institutions have to accommodate to [3]. For example politicians have to adhere to the dramatization style in media discourses, the increasing prominence of short sound bites, visuals and entertainment formats [2], [4]. Hence, political life in its broadest sense has become situated within the domain of media [5]. Media logics thus shape 
not only what gets taken up in the media itself, but also in politics, whose voices get represented and in what way [6]. ${ }^{1}$

What is happening today is that the media, whose logic political institutions are supposed to adhere to, is changing profoundly. This paper focuses on technological processes of digitalization. ${ }^{2}$ There is no doubt that the Internet has changed the media and communication landscape profoundly, both as a phenomenon in itself, and as a locus for established/ traditional mass media to migrate to. The Internet is already established as the main locus for mediated communication and socialization among the young in connected societies [7]. This leads to structural, architectural and social developments with its own significance beyond the technical aspects of digitalization [1], [6]. Not the least digital technology is in a dialectical relationship with sociocultural processes of individualization and reflexivity in late modernity [8], [9], [10], [11], hence I use the term digital late modernity [12]. In other words, digital technology is influencing the way we live, socialize and digital technology is increasingly shaping the way things get done, providing access of information and providing us with new tools for arranging and taking part in all sorts of activities, encounters and social agency [6]. The question then arises what happens with politics and participation when digital technology is starting to claim a dominant position for communication, information and entertainment?

Developments towards a more interactive technology (often described as a web 2.0 or social media) are discussed by some to have far reaching consequences for economy, sociability and not least for politics and participation [13], [14], [15], [16], [17]. The Internet is conceived of as a remedy for all kinds of problem democracy is facing, not least the problem of declining participation in representative democracy [18], [19]. While the Internet no doubt opens up new avenues for engaging in politics, the contribution of this paper to the academic discussion is to put forward a critical perspective of digital technology. The argument is that digital technology disciplines us into certain kinds of behaviors. To conceptualize these relations of power manifested through processes of disciplining, I will outline a concept I claim is emerging in digitalized and late modern societies; a network logic. This paper is thus based on deductive reasoning; when the overall media and communication landscape change, media logics will also evolve, and then politics and participation will be adapting to new circumstances bringing about new types of political participation.

This rather deterministic argumentation where media precedes politics and participation is easily falsifiable in its simplistic and causal reasoning. For example it has been argued that the Internet will not change much when it comes to covering, framing and depicting politics, politicians and elections [20]. However media logics is not only about a causal lineage from media and communication platforms to political institutions. Even though political institutions have become increasingly dependent on

\footnotetext{
${ }^{1}$ For empirical studies see Asp showed how the political system was influenced and adjusted by the demands of mass media and their coverage [21]. A more recent study of the German Parliament from show that the quantity of information related activities have increased sharply whereas the quantity of decision-making activities has remained fairly constant, indicating that politics are becoming increasingly dependent of media coverage [4].

${ }^{2}$ Digitalization should be understood in tandem with processes of deregulation of media ownership, globalization, an increasing number of channels to navigate, and at the same time a concentration of media corporations, increasingly driven by profit maximization [6].
} 
the media, they continue in some measures to control politics and the power of state bodies is still felt in the various communication channels of the Internet [1], [3]. Hence, instead of establishing a causal lineage from media, communication and culture to politics and participation, it is more accurate to conceive of these as in mutual and dialectic relationships to each other [1], [12]. In this paper I will first have to establish the characteristics of new media and digital communication landscape before I can discuss what a new logic looks like and how this new logic is influencing practices of political participation.

\section{Towards a Network Logic}

To establish the characteristics of the emerging media and communication landscape I will turn to Leaning [1] and his extensive literature review on the definitions of so-called new media. He contends that what is often referred to as the new are greater possibilities for convergence, interactivity, continuity, digitization, content that is individually stored and individually produced, greater opportunities for interpersonal communication and more personalized forms of media content. The Internet, digital communication and mobile accesses to the Internet are often referred to when discussing new media. The Internet has now been around for over two decades, but what is often considered as new, is developments awarding greater interactivity, often referred to as web 2.0 or social media. O'Reilly [22] argues that if a website is going to be defined as social, the user must be able to contribute to the content on that site. The user will have the possibility to control his or hers information, and the design is supposed to be interactive. The definition of Social Networking Sites (SNSs from here on) is more elaborate. Ellison \& boyd [23] defines them as different from other sites because they allow the user to articulate their social networks and making them visible to other users. SNSs are thus web-based services allowing individuals to create a (semi)public profile, connecting this profile to other users (often self-selected peers), whose contacts in turn will be made accessible by the service [23]. The major difference from older mass media platforms is the amount of activity demanded of the user. Traditional media are often used more passively, as a background channel feeding the user with information, entertainment or just company. SNSs require the user to be more active, actively search for the kinds of information, entertainment, friends and linkages he or she wants. In this way, the user is also taking part in producing information, entertainment and spheres for social interaction [24], leaving digital footprints behind that could be used for all kinds of purposes (such as marketing or surveillance [25]).

Virtualization of sociability is one consequence of contemporary adaptation to the new media and communication landscape, going hand in hand with an increasing domestication of social institutions and a de-territorialization of cultural experience and social interaction [3], [13]. Already Dewey [26] identified a movement away from the principle of territorial organization in favour of to what he called occupational organization. However, geographic location is still important for identification and socialization, even online, but geographically spread niche networks based in interest are made possible because digital technology makes it easier for like-minded to socialize from their home environments but over great distances [27]. This suggests one character of the emerging network logic that has been widely referred to, the 
increasing possibilities of socializing with like-minded [13], [14], [16], [17]. The main outcome of increasing socialization along lines of like-mindedness rather than geography is unlimited access to culture and content of all sorts [13]. This in turn implies a different and more complex connectivity, depending to a greater extent on cultural reflexivity [3]. For example, instead of passively receiving news, you may today chose/ tailor what news to be served and on what topics. The era of one fits all is thus proclaimed to have ended, and a market of multitudes emerging, with mass market turning into a market of niches, and mass culture turning into a massively parallel culture, in turn making it hard to tell where professionals leave off and the amateurs take over [13], [24].

However, we need to be given ways to find our niches, find like-minded with similar interests [13]. This is where the network enters the arena as an increasingly important filter through which we take part of information and conceive of the world. Through networks of peers and like-minded we reflexively organize our social life, interact with each other, share and get information. Interactivity and interpersonal communication, which is celebrated as aspects of the newness of the Internet and digital communication, concerns activities and issues going on between people. This requires continuous communication. Given the increasing mobility of communication platforms and mobile access to the Internet through smart-phones, expressions and maintenance of network connections are taking place all the time, or at least have the possibility to take place all the time. I would thus argue that an important aspect of the emerging network logic is that it disciplines us to be constantly updated in the double sense of the word - to be updated of the doings in the network as well as update the network of our doings, thoughts and feelings. Livingstone's [27] study of British teenagers use of SNSs underlines updating as a central practice. If someone comments on a profile they are most likely will be commented back and therefore some teenagers spend hours going from one profile to another to leave comments, something Livingstone conceives of as a necessity on order to reaffirm one's place within the peer network. Referring to my students' media diaries, it seems that the mere risk of missing out of something pushes them to have their smart phones with them and turned on wherever they are 24/7. The network logic thus pushes us to be updated in a double sense.

Increasingly important characteristics of the emerging network logic must be responsiveness and connectedness. This is illustrated in a study of the cell phone where informants claimed that the phone enriched their social life, furthering opportunities for selfexpression at the same time as managing and remaking relationships with friends and family [28]. On SNSs more prominence is put on so-called friends ${ }^{3}$ and links to others than on the text being produced [29]. Less space is allowed for actual text than links to others. What seems to be at stake is the position within the peer network [27]. Hence, on SNSs, the most important list is the list of friends and the point of social networking is to establish and demonstrate linkages and connections, rather than to engage in dialogic communication [29]. The larger the network the more secure the individual. And today large networks are possible because of digital technology such as e-mail, text messaging, SNSs and smart-phones. People are continually in touch because technologies even

\footnotetext{
${ }^{3}$ Friend is becoming an increasingly non-sophisticated way of labeling visible contacts online as Livingstone [33] points out.
} 
stand in for us, leading to a kind of connected presence in which we are constantly contactable. Hence Miller [29] proclaims content is not king, but keeping in touch is, further underlining connectivity and responsiveness as important values in the emerging network logic.

The urge to manage lists of friends and linkages to others will lead us to a shift from the narrative as a key form of cultural expression to the database as the prominent cultural form in digital late modernity [30]. Databases are always in progress and thus the management of them can never be finalized [30], and digital technology enable communication among an ever-widening circle of contacts [27]. Hence the emerging network logic disciplines us to build and maintain our networks and possible surfaces of contact. Digital technology enable/disciplines us to codify, map and view relational ties between ourselves and others [27]. The web has thus become an endless and unrestricted collection of texts, images, data records, sound bites, whose purpose it is to efficiently store and retrieve for potential later usage [29]. Foucault [31], when outlining the different characteristics of power in what he labels disciplinary society, ${ }^{4}$ refers to the power to extract and make use of knowledge from individuals and about individuals. Today when we freely engage in this surveillance on SNSs, the possibilities of this type of power are multiplied and thus the possibilities for database management also increases.

Intertwined with the increasing importance of managing and sustaining our networks through practices of updating, the network logic underlines processes of identification and reflexivity, resonated in theories of late modernity [8], [9], [10], [11]. A continuous emphasis of the self as something that can be managed, is put upon the individual to such a degree that the self becomes a reflexive project [10]. The question who are we arises at the end of the $18^{\text {th }}$ century [32]. Supervision in this time of reflexivity is carried out at the level of what one is rather than what one does [31]. It thus seems that the late modern self, anxiously trying to confirm who she really is, uses digital technology to both monitor her identity as well as reaffirming it in front of selected others/peers. This takes the form of reflexive connectivity and reflexive responsiveness when making links to other users public (as well as causes, organizations, brands) and hence freeloading on their supposed connotations, connotations to which we whish to tie images of our selves [33]. Individuality is then both fostered, and dependent on the network since we most likely will be ignored without network visibility with references to other users.

Through digital technology we negotiate ourselves, and the other is incorporated into this negotiation, underlining a form of networked individualism [34], particularly illuminating for understanding the practice of linking the self to different users and networks in digital late modernity. Social networking online is becoming an integral means of managing one's identity, expressing who you are to others [27]. Hence, being updated (in the double sense) is as much about the self as it is about the other, the collective or rather the network. As Livingstone's [27] study show, British teenagers tend to foreground their links to others, expressing a notion of identity lived through managing authentic relationships. Hence online communication is not so much about narcissism as it is about embedding the self within the peer group [27]. We are thus dealing with identity through connectivity. Digital technology has enabled individuals to act as social

\footnotetext{
${ }^{4}$ This refers to a society that emerges $n$ the late $18^{\text {th }}$ century beginning of $19^{\text {th }}$ century.
} 
switchboards, centre points for multiple changing and overlapping networks of interaction. Already Dewey [26] pointed out that the individual could not be understood without considering his associations with others. Similarly Arendt [35] underlined the presence of others to assure us of the reality of the world and ourselves.

We should thus not underestimate the disciplining effects of the new kinds of social practices online. It is almost as digital communication platforms pressure us to engage in continuous reflexive self-presentations, always ready to respond, connect and update. This is one reason to focus on a network logic in order to underline that these practices also carries with it a logic based in other kinds of norms and values to which we have to position ourselves. For example, blog norms and values gets revealed in policing practices of newbies who have to earn the personal respect of others through establishing their presence over time, demonstrating commitment to the community [36]. According to Foucault [31] we are in the midst of a disciplinary society, an age of social control that started at the end of the $18^{\text {th }}$ century. What is constitutive of this society is that power is exercised through disciplining (and not through sovereignty), normalizing power and the knowledge-power formations that support these largely discursive practices. The control of individuals started to be performed by a series of authorities and networks of institutions of surveillance and correction (not only the judiciary) such as the police and the psychological, psychiatric, criminological, medical and pedagogical institutions [31]. Disciplining should thus be understood as increasingly controlled and rationalized processes of adjusting activities, communication networks and power relations [37]. Hence, power is a type of relationship between people, influencing others actions rather than acting immediately upon others. In other words, the exercise of power disciplines people to act in certain ways, in turn structuring the field of further possible actions [37]. These power relations are rationalized through different logics operating in different contexts. For example social control was used at the end of the $18^{\text {th }}$ century in relation to the formation of capitalist society as a way to protect economic wealth [31]. The question here is what social control is used for in digital late modernity? How does the network logic discipline the users of digital technology, and into what kinds of behaviors? Preferred behavior online, to be successful on digital communication platforms, you need to master a slightly new form of sociability, through database and friend management and through constant updating, negotiating and maintaining an attractive self on as many stages as possible in order for peers to visit your digital profile, leave comments and reaffirm your identity(ies) [27]. This is a kind of power that reveals it-self in the continuous preoccupation with expressing and negotiating our selves and our positions, as well as interpreting others through the production, maintenance and sustenance of network visibility. Social control today would be the constant monitoring/ supervision of both oneself and others through practices of updating. Foucault's discussions of power can be applied remarkably well on digital communication platforms. He outlines a form of power that makes individuals into subjects, ties them to their identity by conscience and self-knowledge [37]. In other words the late modern reflexive subject is, following Foucault, a result of a form of power exercised upon it through surveillance that individuals willingly submit them selves to through practices of online networking.

Visibility and power has always been connected but in different ways across times [38]. When in antiquity the visibility of the few to the many was connected to power, 
in modernity being watched was connected to a subordinate position of being disciplined, a more subtle normalizing power of the gaze (in schools, armies, hospitals, penal institutions et cetera). In digital late modernity we are all visible all the time through a type of connected presence. This resonates with Foucault's [31] wellknown discussion of the panopticon..$^{5}$ We are objects of the constant gaze of others, but what is different today is that we are participating in this disciplining by free will in order to secure a place on the social arena and to negotiate an attractive self. In fact it is not all obvious whether being watched online and being used by others in their identity negotiation is exercising power or being subordinate to power. It all depends how skillfully the user navigates the new social arena and manages his or hers databases of friends and connections, how skillfully the user governs his or hers visibility in the different contexts and front stages digital technology offers. Foucault [31] underlines that the individuals over whom power is exercised are those from whom the knowledge they themselves produce are extracted and used in order to control them. The central question today is thus to decide what shall be public and to whom. This decision is to a large extent put in the hand of the everyday user of digital technology. At the same time the network logic disciplines us to self-revelations online in order to reaffirm ones position in the social arena.

Another way of illustrating power relations in networks is through the metaphor of a filter, a network of peers influencing our decisions. Anderson [13], who has theorized about Internet economy as a long tail of niche markets, summarizes the long tail in two principles, 1) making everything available and 2) helping us finding it. It is especially in the second principle relations of power comes into play. In the increasing buzz of information in digital late modernity, it is impossible to make an informed decision on what to choose. Life choices seem to be multiplying and the responsibility for making the right choices are increasingly put on the individual when modern institutions (family, church, social movements) looses in relevance. We are experiencing an ever-expanding range of elective identities that may be easily embraced or rejected. In other words we need guidance and this is one way our networks are increasingly influential, amplifying certain sites, while sorting out others since it would be impossible for us to process the value of all the different sites on offer [13]. The network thus works as peer power/ pressure, informing us about the variety of choices but also what others before us have done in similar situations.

The network function as a filter, as a group of peers guiding/ influencing us in our choices, and the network disciplines us to share our experiences and making our choices and visible to others (the constant updating), argued by some to lead to a self-endorsed surveillance society [25]. This is where I whish to return to the kind of reflexive expressiveness I have argued is the dominant rationale for our updating practices [12]. Also Anderson [13] discusses expressiveness as a motivator. Down in the tail where distribution and production costs are low, business considerations are often secondary. Instead people create for other reasons such as expression, fun and reputation [13]. Getting noticed is everything. Arendt [35] notices that the public realm in ancient Greece was reserved for individuality and thus permeated by a spirit where everybody had to distinguish him or herself. Hence she points at the inevitability in politics of men

\footnotetext{
${ }^{5}$ Following Bentham, Foucault discusses a mechanism of surveillance where one can supervise the many.
} 
disclosing themselves, though speech and action, as subjects, as distinct and unique persons. In my own work I have labelled expressive rationality as the motivational force in the digital late modernity [12]. With the increasing possibility of identity, a kind of do it your self-biographies emerges [27], [36]. In other words users of digital technology are becoming more self-expressive.

In conclusion, it is through a network logic of connectedness and responsiveness, users of digital technology are disciplined into behaviours of continuous updating and reflexive self-presentations. Following the analogy with media logics and mediatization presented in the introduction, it is to this though this network logic that politics and participation is supposed to adapt. In the next and concluding section I will situate the above discussion of the network logic more specifically in the realm of politics and participation.

\section{Network Logic and E-Participation}

When it comes to the de-territorialization of cultural experience and social interaction, digital technology seems to be accompanied with logics where not least placeless communication and mobility challenge the rather geographically bounded character of traditional political participation and sociability [6]. At the same time there seems to be a trend in a seemingly opposite direction, towards the local and neighbourhood. The domestication of social institutions afforded by digital media together with increasing reflexivity and blurring between boundaries of the public/ private dichotomy in late modernity, tend to underline single-issue engagement rooted in the local and everyday life experiences rather than in grand ideologies of modernity. Both these trends turn their back on the nation state as the defining boundary for political participation since participation in digital late modernity to a larger extent is organized around identity and lifestyle as Giddens' [10] concept life politics indicates.

The need to feel connected to an issue, evoking some kind of identity, has proven to be an important incentive for communication on websites set up by political institutions for civic deliberation [15]. This I argue will be increasingly the case since the network logic pushes us to share our experiences through processes of updating. Then our choices of arenas and topics for political participation will be carefully and reflexively chosen since it will be increasingly likely that we share our doings in different digital networks. Life politics demands a certain kind of self-reflexivity in terms of making conscious choices on what to engage in, since this will be visible online and surveilled by like-minded and peers. Late modern individualisation is thus not only about the liberation of the individual from social regulation in modern institutions (such as the family, church and social movements) but also a demand to supply our life stories, to import our selves into our biographies through our own actions (Beck \& Beck-Gernsheim, discussed in Leaning [1]).

It has been claimed that in the market of niches and multitudes afforded by digital technology, it is hard to tell where professionals leave off and the amateurs take over [13], [24]. This points towards both a personalization and de-professionalization of political participation. De-professionalization applies mainly to the lowering of threshold for anyone to launch a life-political campaign digitally, organize an online 
petition or engage and inform oneself in a reflexively selected topic. ${ }^{6}$ Personalization relates to the salience of individual identity for making participation relevant as discussed previously. Personalization is also a trend in professional politics accompanied by the increasing use of SNSs [39]. The network logic seems to be push politicians to be more personal when appearing in different media and communication platforms. Not least it seems that personality is used as a resource for attracting participation and support, which could be understood in light of the increase of reflexive participation in digital late modernity. When identity management becomes part of political participation, people will more likely tie their engagement to attractive personalities, personalities they whish to connect their selves and their biographies to. Digital communication platforms increases the possibility of identity negotiation and management through displaying links to others and causes and their supposed connotations, further underlining and pushing for reflexive do-it-yourself-biographies as part of participatory practices [33], [36].

The peer-network Livingstone [27] underlines in her study of British teenagers is also at work in political networks. My own study of a politician's use of SNSs indicates that politicians are more likely to comment among each other and within the party community than with outsiders and potential voters, even though this often is the explicit aim when using SNSs [40]. This confirms Millers [29] conclusion that the point of social networking is to establish and demonstrate linkages and connections, rather than to engage in dialogic communication. This also contradicts the utopic visions deliberative democrats have projected on the Internet under web 2.0 with its promise of interactivity [18], [19]. Surely people interact online, but this interaction seems to take place among like-minded to a larger degree than with people of diverging opinion. ${ }^{7}$ What we witness online is rather identity through displaying connections with peers than rational communication towards consensus. It thus seems that the late modern self, regardless if it is a politician or a teenager, is anxious to confirm who she really is and thus uses digital media to both monitor her identity as well as reaffirming it in front of selected others. In other words participation in general is becoming more self-expressive.

One implication on political participation of values of connectivity and responsiveness through practices of updating would be that we tend to reveal our political interests to a larger extent in digital late modernity. An American study from the 2008 presidential campaign showed that 20 percent of the survey sample had discovered the political interests of their friends by using SNSs [42]. This seems to counter Eliasoph's [43] well-known ethnographic study of American volunteers, where she contends that people tend to avoid politics. Through a network logic, where updating and sharing practices are highly valued, users are to a less extent shying away from making their political opinions visible to others in the network. Not only will we monitor and classify our connections (friends) online, we are also making ourselves subject to surveillance through displaying our selves, life choices and political preferences. In this way the information we share may be used to target information to us, not only

\footnotetext{
${ }^{6}$ When it comes to professional politics the increasing use of spin-doctors and communication advisors rather points towards professionalization of politics.

${ }^{7}$ Sunstein [41] claims this leads to in group polarization rather than consensus.
} 
for commercial purposes, but also for political spin, for professional political campaign strategist to tailor messages to specific target groups.

We use the Internet as a database of texts, images, data records, sound bites, and sometimes store this for later usage [29]. When participation move online, websites are envisioned and designed as resources for its users to access and become informed about the various political perspectives and plans in our surroundings and spheres of interest [15]. In other words governmental, NGO and activist websites are not only used as tools for reflexive identity management, but also often supposed to function as databases for information gathering. Arguably one consequence of subscribing to newsletters, e-mail lists, joining facebook groups and linking our online personas to different reflexively chosen causes and politicians, is that we may potentially become engaged and participate when proposed actions fit with our life stories and can be combined with our every day life.

In this paper I have discussed the emerging network logic and how it intersects and work in tandem with evolving participatory practices online. When media and communication landscape change, participation will also evolve since media, communication and political participation are mutually dependent on each other. Digital technology is no doubt a wonderful thing, connecting people across the globe often lowering the threshold for political participation. However the emerging media and communication landscape is not free from relations of power. Therefore as critical scholars we need to attend to how the network logic disciplines users in different ways, favoring certain behaviors over others. Though we should be somewhat careful with an allencompassing detached network metaphor. We operate in many different networks at the same time, where somewhat different logics dictate because of different contexts [44]. Participating on an activist group's facebook page differs from participating in the mummy group online, even though the two groups may consist of largely the same persons. Digital networks and online interactions should also not be exaggerated over relative positions and field specific capital in localized offline environment [44]. Hence, network logic cannot be understood without contextualizing in what social fields the network interaction takes place.

\section{References}

1. Leaning, M.: The Internet, Power and Society: Rethinking the Power of the Internet to Change Lives, Chandos, Oxford (2009)

2. Altheide, D.L.: Media Logic and Political Communication. Political Communication 21, 293-296 (2004)

3. Hjarvard, S.: The Mediatization of Society A theory of the Media as Agents of Social and Cultural Change. Nordicom Review 2008(2), 105-134 (2008)

4. Kepplinger, H.M.: Mediatization of Politics, Theory and Data. Journal of Communciation, 972-986 (December 2002)

5. Street, J.: Politics and Popular Culture. Polity Press, Cambridge (1992)

6. Dahlgren, P.: Media and Political Engagement. Citizens, Communication, and Democracy. Cambridge University Press, New York (2009)

7. Medierådet: Unga \& Medier. Fakta om barns och ungas användning och upplevelser av medier (Youth \& Media 2010. Facts about children's and youths' use and perceptions of media), Kulturdepartementet, Stockholm (2010) 
8. Bauman, Z.: The Individualized Society. Polity Press, Cambridge (2001)

9. Beck, U.: Att uppfinna det politiska; Bidrag till en teori om reflexiv modernisering. To Invent Politics. Contribution to a Theory of Reflexive Modernization, Daidalos, Göteborg (1995)

10. Giddens, A.: Modernity and Self-Identity: Self and Society in the Late Modern Age. Polity Press, Cambridge (1991)

11. Lasch, C.: The Culture of Narcissism. American Life in an Age of Diminishing Expectations. W. W. Norton \& Company, New York (1991), first published 1979

12. Svensson, J.: The Expressive Turn of Citizenship in Digital Late Modernity. JeDEM eJournal of eDemocracy 3(1), 42-56 (2011)

13. Anderson, C.: The Long Tail - How Endless Choice Is Creating Unlimited Demand. Random house business books, London (2006)

14. Benkler, Y.: The Wealth of Networks: How Social Production Transforms Markets and Freedom. Yale University Press, New Haven (2006)

15. Hilts, A., Yu, E.: Modeling Social Media Support for Elicitation of Citizen Opinion. In: MSN 2010, Toronto, ON Canada (June 13, 2010)

16. Jenkins, H.: Convergence Culture. Where Old and New Media Collide. New York university Press, New York (2006)

17. Shirky, C.: Here Comes Everybody. How Change Happen when People Come Together. Penguin Books Ltd., London (2009)

18. Coleman, S., Blumler, J.: The Internet and Democratic Citizenship: Theory Practice and Policy. Cambridge University Press, New York (2009)

19. Kies, R.: Promises and Limits of Web-deliberations. Palgrave MacMillan, New York (2010)

20. Schweitzer, E.: Mediatized Politics on the Internet. Evidience From a Multi-Level Analysis of German Online Campaigns in State, National, and European Parliamentary Elections. Paper presentedt at the 3rd Eurpoean Communication Conference of the European Communication Research and Education association (ECREA), Hamburg, Germany (2010)

21. Asp, K.: Mäktiga massmedier: Studier om politisk opinionsbildning. Powerful Mass Media: Studies of Political Opinion Formation. Akademilitteratur, Stockholm (1986)

22. O'Reilly, T.: What Is Web 2.0. Design Patterns and Business Models for the Next Generation of Software (2005), http: / / www . oreilly.com/web2/archive/what-isweb-20.html

23. Ellison, N., boyd, d.: Social Network Sites: Definition, History and Scholarship. Computer-Mediated Communication 13(1) (2007)

24. Bruns, A.: Blogs, Wikipedia, Second Life, and Beyond. From Production to Produsage. Peter Lang, New York (2008)

25. Andrejevic, M.: I Spy: Surveillance and Power in the Interactive Era. University Press of Kansas, Lawrence (2007)

26. Dewey, J.: The Public and its Problems. Ohio University Press, Athens (1927)

27. Livingstone, S.: Taking Risky Opportunities in Youthful Content Creation: Teenagers' Use of Social Networking Sites for Intimacy, Privacy and Self-expression. New Media \& Society 10(3), 393-411 (2008)

28. Pröitz, L.: Mobile Media and Genres of the Self. In: Storsul, T., Stuedahl, D. (eds.) Ambivalence Towards Convergence: Digitalization and Media Change, Nordicom, Göteborg (2007)

29. Miller, V.: New Media, Networking and Phatic Culture. Convergence - The International Journal of Research into New Media Technologies 14(4), 387-400 (2008) 
30. Manovich, L.: The Language of New Media. MIT Press, Cambridge (2001)

31. Foucault, M.: Truth and Juridical Forms. In: Faubion, J.D. (ed.) Power - Essential Works of Foucault 1954-1984, vol. 3. Penguin Books, London (1994), first published 1973

32. Foucault, M.: The Political Technology of Individuals. In: Faubion, J.D. (ed.) Power - Essential Works of Foucault 1954-1984, vol. 3. Penguin Books, London (1994), first published 1988

33. Donath, J., boyd, D.: Public Displays of Connection. BT Technology Journal 22(4) (2004)

34. Castells, M.: The Internet Galaxy: Reflections on the Internet, Business and Society. Oxford University Press, Oxford (2001)

35. Arendt, H.: The Human Condition, 2nd edn. The University of Chicago Press, Chicago (1998), first published 1958

36. Hodkinson, P.: Interactive Online Journals and Individualization. New Media \& Society 9(4), 625-650 (2007)

37. Foucault, M.: Subject and Power. In: Faubion, J.D. (ed.) Power - Essential Works of Foucault 1954-1984, vol. 3, Penguin Books, London (1994), first published 1982

38. Thompson, J.B.: Medierna \& moderniteten. Media and Modernity, Daidalos, Göteborg (2001), first published 1995

39. Anduiza, E.: The Internet, election campaigns and citizens: state of affairs. Quaderns del CAC, 5-12 (December 2009)

40. Svensson, J.: Nina on the Net. A Study of A Politician campaigning on Social Networking Sites. Central European Journal of Communication (2011) (forthcoming)

41. Sunstein, C.: Republic.com. Princeton University Press, Princeton (2001)

42. Zhang, W., Johnson, T.J., Seltzer, T., Bichard, S.L.: The Revolution Will be Networked. The Influence of Social Networking Sites on Political Attitudes and Behavior. Social Science Computer Review, 75-92 (Feburary 2010)

43. Eliasoph, N.: Avoiding Politics: How Americans Produce Apathy in Everday Life. Cambridge University Press, New York (1998)

44. Postill, J.: Localizing the Internet beyond Communities and Networks. New Media \& Society 10(3), 413-430 (2008) 